\title{
CONVERSAS COM... SOBRE A DIDÁTICA E A PERSPECTIVA MULTI/INTERCULTURAL
}

\author{
Vera Maria Candau ${ }^{*}$ \\ Adélia Maria Nehme Simão e KofF*
}

RESUMO: Focaliza como a perspectiva multi/intercultural está sendo incorporada pelos profissionais do campo da didática. A partir da análise de 20 depoimentos, discute-se como esses profissionais estão percebendo as contribuições e os temas que emergem quando se analisam as relaçôes entre didática e multiculturalismo e também os riscos e os desafios inerentes a essa temática. Entre preocupações e possibilidades, os entrevistados apontam questōes de particular importância, tais como: tensão entre social e cultural, articulação igualdade e diferença, bem como a problemática do universalismo versus relativismo cultural. São aspectos relevantes que vimos trabalhando em diferentes projetos de pesquisa, em particular no projeto Ressignificando a didática na perspectiva multilintercultural, com o objetivo de ultrapassar uma visão dicotômica entre esses pólos. Nossa intenção é contribuir para a construção de uma didática crítica "atravessada” pela perspectiva multi/intercultural.

Palavras-chave: Didática crítica. Diferença. Multiculturalismo. Educação intercultural.

\section{CONVERSATIONS WITH...}

Multicultural CURRICULUM AND INSTRUCTION

ABSTRACT: This paper focuses on how a multicultural-intercultural perspective is being incorporated by Curriculum and Instruction specialists. Based on the analysis of twenty interviews, it discusses how the specialists perceive the contributions and themes arising from the relationship between instruction and multiculturalism.

* Professora Titular do Departamento de Educação da Pontifícia Universidade Católica do Rio de Janeiro (PUC-RIO). E-mail: vmfc@edu.puc-rio.br

** Doutoranda do Departamento de Educação da PUC-RIO. 
Conversas com... sobre a didática e a perspectiva multi/intercultural

It also outlines the risks and challenges inherent to the topic. Among concerns and possibilities, the interviewees brought up a number of crucial issues such as the tension existing between a social and a cultural perspective, the articulation between equality and difference and the relationship between universalism and cultural relativism. These are some of the relevant topics we have explored in different research projects, particularly one entitled Ressignificando a didática na perspectiva multi/intercultural, which aimed at overcoming a dichotomic vision of these two concepts. Our purpose is to contribute to the development of a Critical Pedagogy suffused by the multi/intercultural perspective.

Key words: Critical pedagogy. Difference. Multiculturalism. Intercultural education.

V

imos desenvolvendo, desde 1996, com o apoio do CNPq, uma linha de pesquisas que se vem desdobrando em diferentes projetos, cujo objeto central tem sido o estudo das relações entre educação e cultura(s) em diferentes espaços educativos, tendo por principal finalidade contribuir para o aprofundamento dessa problemática e oferecer elementos para que as práticas pedagógico-didáticas possam ser repensadas e/ou reinventadas, incorporando, de maneira crítica, a questão das diferenças culturais, na pluralidade de suas manifestaçóes e dimensões.

Nesse contexto, o projeto intitulado Ressignificando a didática na perspectiva multilintercultural desenvolveu-se motivado pela busca de respostas a questôes como: $\mathrm{O}$ que significa uma didática "atravessada" pela perspectiva multi/intercultural? Como essa perspectiva está penetrando esta área de conhecimento? Que elementos básicos devem ser considerados na realização de um processo de ressignificação da didática nessa perspectiva? Como trabalhá-los nos cursos de didática voltados para a formação inicial e continuada de professores?

Dada a abrangência e a complexidade destas questóes, bem como a riqueza dos dados obtidos como fruto da referida pesquisa, propomo-nos a apresentar, neste texto, apenas uma análise parcial desses dados, procurando responder, principalmente, a uma de nossas questões - como a perspectiva multi/intercultural está sendo incorporada pelo campo da didática e, no caso específico, na visão de seus próprios protagonistas, ou seja, professores, pesquisadores e estudiosos do campo. 
Assim, este trabalho tem como objetivo central apresentar e analisar como esses profissionais se posicionam com relação à construção de uma didática marcada pela perspectiva multi/intercultural.

\section{Perspectiva multi/intercultural: eixos de discussão}

Muitos têm sido os suportes teóricos sobre os quais nos temos apoiado para fundamentar nossas reflexões, estudos e pesquisas. Vale dizer que inúmeros textos elaborados pelos diferentes integrantes de nosso grupo de pesquisa, e que se encontram à disposição para consulta, seja em anais de diferentes seminários e/ou encontros, dentre os quais destacamos aqueles relacionados aos ENDIPEs, seja em nosso próprio banco de dados (consultar http://www.gecec.pro.br), seja como artigos ou capítulos de livros (Candau, 2000; 2002; 2003; 2005), já apontaram os referenciais teóricos e/ou autores com os quais estamos dialogando desde o início do nosso trabalho e que têm servido para fundamentar nossas análises.

Todavia, consideramos oportuno e necessário apresentar, no âmbito deste trabalho, uma síntese, mesmo que breve, dos principais eixos sobre os quais vimos trabalhando. São eles: a) globalização e multiculturalismo; b) relação entre igualdade e diferença; c) tensão universalismo - relativismo cultural; d) didática e perspectiva multi/ intercultural.

Atualmente, o fenômeno da chamada globalização representa um verdadeiro quebra-cabeças para pensadores e cientistas de diferentes áreas do conhecimento. Parece-nos que não há como negar que se trata de uma realidade complexa, que nos afeta a todos e que não pode ser reduzida a uma única variável. Ao contrário, acreditamos que a globalização envolve diferentes dimensões - econômica/social, política, cultural, tecnológica, incluindo, neste caso, os avançados meios de informação e comunicação -, que se entrelaçam e não podem ser analisadas de modo isolado.

Vale lembrar que há autores os quais afirmam que se trata de um processo profundamente padronizador das sociedades, dos imaginários coletivos e das mentalidades. E que outros destacam que, porque gera resistência e uma renovada consciência das identidades culturais, a globalização provoca uma nova emergência e a mobilização de movimentos identitários de caráter local e internacional. 
Conversas com... sobre a didática e a perspectiva multi/intercultural

Por isso, reconhecemos que a globalização é um fenômeno complexo e plural. E em consonância com as reflexóes e contribuiçóes de Santos (1997), que nos alerta para o fato de que existem vertentes da globalização, que podem ser agrupadas em duas categorias, ou seja: uma globalização de "cima-para-baixo" que tende à homogeneização e outra de "baixo-para-cima" que reconhece a diversidade, assumimos uma perspectiva dialética e multidimensional para lidar com as questôes da relação entre globalização e multiculturalismo, reconhecendo que não há uma só globalização e que, dependendo de suas características, ela vai se relacionar de diferentes maneiras com o multiculturalismo.

Entretanto, não podemos deixar de destacar que o processo de globalização de "cima-para-baixo" ainda é hegemônico, parece irreversível e vem suscitando muitas discussões, resistências e críticas radicais.

Também inspiradas em Santos (2003), assumimos a idéia de que é preciso articular igualdade e diferença, entendendo que o que se opõe à igualdade é a desigualdade e à diferença é a padronização. "As pessoas e os grupos sociais têm o direito de ser iguais quando a diferença os inferioriza, e o direito de ser diferentes quando a igualdade os descaracteriza" (p. 10). E, neste sentido, acreditamos que é oportuno acrescentar que "não se pode pensar numa igualdade que não incorpore o tema das diferenças, o que supõe lutar contra todas as formas de desigualdade, preconceito e discriminação" (Candau, 2003, p. 6).

Quanto à tensão entre universalismo e relativismo cultural, de grande relevância para a ação educativa, em especial para as questões curriculares, entendemos que, nos dias de hoje, é preciso que nos situemos de maneira crítica, seja no que se refere aos chamados conhecimentos e valores universais, seja no que diz respeito ao relativismo cultural radical. O que estamos querendo afirmar é que é necessário, ao mesmo tempo, questionar a idéia da existência de conhecimentos e valores considerados universais (quase sempre centrados na cultura ocidental e européia), e cuidar para não cair

Num relativismo absoluto, reduzindo a questão dos conhecimentos e valores veiculados pela educação formal a um determinado universo cultural, o que nos levaria inclusive a negar a própria possibilidade de construirmos algo juntos, negociado entre diferentes, e à guetificação. (Candau, 2003, p. 6) 
Cientes de que existem diversos modos de entender o multiculturalismo e, conseqüentemente, modelos de educação multicultural, e, ainda, levando em conta diferentes conceitos de cultura e que esses conceitos e abordagens precisam ser permanentemente explicitados, nossos trabalhos de pesquisa, nesse contexto de intensa pluralidade de concepçōes, privilegiam a perspectiva intercultural. Neste ponto, vale afirmar que podemos encontrar na literatura um amplo debate sobre as diferenças e aproximações entre multiculturalismo e interculturalismo, bem como sobre seus impactos na educação. A respeito disso há uma série de reflexões, dentre as quais podemos citar as obras de Jordan (1996), Bartolomé Pina (1997), McLaren (1997 e 2000), Banks (1999), Forquin (2000), Abdallah-Pretceille (2001), entre outros, mas que no âmbito deste trabalho não nos cabe aprofundar.

Todavia, consideramos oportuno destacar que, sintonizadas com Forquin, assumimos, que "o multiculturalismo é, de um lado, um dado da realidade - vivemos em sociedades multiculturais. Por outro lado, supóe uma tomada de posição diante dessa realidade, do ponto de vista teórico e das práticas sociais e educativas" (Candau, 2003, p. 18).

No que se refere ao interculturalismo, nós o consideramos

Como um enfoque que afeta a educação em todas as suas dimensões, favorecendo uma dinâmica de crítica e autocrítica, valorizando a interação e comunicação recíprocas, entre os diferentes sujeitos e grupos culturais.

A interculturalidade orienta processos que têm por base o reconhecimento do direito à diferença e a luta contra todas as formas de discriminação e desigualdade social. Tenta promover relações dialógicas e igualitárias entre pessoas e grupos que pertencem a universos culturais diferentes, trabalhando os conflitos inerentes a esta realidade. Não ignora as relações de poder presentes nas relaçôes sociais e interpessoais. Reconhece e assume os conflitos procurando as estratégias mais adequadas para enfrentálos. (Idem, ibid., p. 19)

Educar na perspectiva intercultural implica, portanto, uma clara e objetiva intenção de promover o diálogo e a troca entre diferentes grupos, cuja identidade cultural e dos indivíduos que os constituem são abertas e estão em permanente movimento de construção, decorrente dos intensos processos de hibridização cultural (ver Stuart Hall, 1997a e 1997b; e Nestor Garcia Canclini, 1991, 1995, 1997 e 1999). 
Conversas com... sobre a didática e a perspectiva multi/intercultural

Neste sentido, a abordagem intercultural que privilegiamos se aproxima do multiculturalismo crítico e revolucionário de McLaren (1997 e 2000), que parte da afirmação de que o multiculturalismo tem de ser situado a partir de uma agenda política de transformação, sem a qual corre o risco de se reduzir a outra forma de acomodação à ordem social vigente. Entende as representaçôes de etnia, gênero e classe como produto de lutas sociais sobre signos e significaçôes. Privilegia a transformação das relações sociais, culturais e institucionais nas quais os significados são gerados. Recusa-se a ver a cultura como não-conflitiva, argumenta que a diversidade deve ser afirmada "dentro de uma política crítica e compromisso com a justiça social” (1997, p. 123).

Nos últimos 20 anos, uma ampla produção científica tem sido desenvolvida na área de didática. E, com freqüência, tal produção tem sido objeto de sínteses e análises críticas, apresentadas, especialmente, durante os Encontros Nacionais de Didática e Prática de Ensino ENDIPEs. Neste sentido, Oliveira, durante o X ENDIPE, faz referências aos diferentes eixos que nortearam os vários simpósios realizados por ocasião do IX ENDIPE, em 1998, destacando um eixo sobre novos desafios às práticas em sala de aula, que representaria

Um anúncio de um espaço agora mais formalizado, para as questões atuais das novas tecnologias, a discussão do multiculturalismo e da educação para a cidadania e os direitos humanos. Essas questôes vinham batendo às portas dos ENDIPEs, buscando conquistar espaço, desde o VII Encontro, quando já aparecem em alguns dos conteúdos de alguns dos estudos apresentados. (McLaren, 2000, p. 172)

A partir dessa afirmação, fica evidente o lento e recente processo de incorporação das questốes relativas ao multiculturalismo nos estudos e nas pesquisas no campo da didática, podendo ser situadas a partir, praticamente, da segunda metade da década de 1990, já que o VII ENDIPE realizou-se em 1994.

Em síntese, estas são algumas anotações que expressam o suporte teórico que vem fundamentando nossas análises e que, no caso específico deste trabalho, ajudaram-nos a "olhar" para os depoimentos dos profissionais da área de didática, buscando perceber como as questões do multiculturalismo estão ou não sendo apropriadas por eles/elas e, se estão, como estão. 


\section{O caminho percorrido}

Cabe aqui registrar que, do ponto de vista metodológico e no que tange à plena realização da pesquisa Ressignificando a didática na perspectiva multilintercultural, adotamos diferentes e amplos procedimentos que incluíram a análise de conteúdos - no caso, dos trabalhos apresentados nas reuniōes anuais da ANPED e nos ENDIPEs de 1994 a 2002 - e entrevistas individuais com diferentes especialistas - professores(as) e pesquisadores(as) do campo da didática -, assim como o desenvolvimento de um curso de didática para futuros(as) professores(as) atravessado pela perspectiva multi/intercultural, e inspirado na metodologia da pesquisa-ação.

Vale reiterar que vamos nos deter apenas na análise desses depoimentos que foram coletados, entre 20 profissionais, durante o XII ENDIPE, que aconteceu em Curitiba, em 2004, e durante a Reunião Anual da ANPED, realizada nesse mesmo ano, em Caxambu.

Para a seleção desses(as) especialistas foram adotados critérios que podem ser assim sistematizados: freqüência significativa e contínua no GT de Didática da ANPED, participação sistemática nos ENDIPEs, comprovação de expressiva produção acadêmica na área e representatividade regional.

O roteiro utilizado nas entrevistas semi-estruturadas foi objeto de um intenso e detalhado processo de elaboração com a participação de todos os componentes da equipe. As entrevistas foram realizadas após prévio contacto via e-mail com os(as) professores(as) selecionados(as). Realizaram-se em um clima de diálogo e cordialidade, tendo em média uma duração de 60 a 80 minutos, sendo todas gravadas, com prévia autorização dos(as) entrevistados(as). As transcrições das fitas foram realizadas por diferentes membros da equipe e outros profissionais com preparação adequada, e foram revisadas pelas entrevistadoras, sempre que estas não foram as responsáveis pelas transcrições. Quando solicitado, enviou-se a transcrição aos(às) próprios(as) entrevistados(as).

\section{Caracterização dos entrevistados}

Nossos entrevistados podem ser assim caracterizados: quatro (4) professores e dezesseis (16) professoras que atuam em universidades públicas e/ou privadas nos estados de São Paulo, Rio Grande do Sul, 
Conversas com... sobre a didática e a perspectiva multi/intercultural

Minas Gerais, Goiás, Paraná, Mato Grosso, Pernambuco e também em Brasília. Seus depoimentos foram realizados a partir de um roteiro semi-estruturado de entrevista, em um clima marcado pela cordialidade, disponibilidade e pelo interesse em contribuir para o desenvolvimento da pesquisa.

São professores(as) que, em geral, possuem uma ampla experiência e uma trajetória profissional que, para um número significativo deles(as), tem aproximadamente 30 anos e está intimamente relacionada com o desenvolvimento do campo da didática, a partir, principalmente, do final dos anos de 1970 e início dos anos de 1980. Vários(as) deles(as) são protagonistas e atores centrais no processo de ressignificação da didática que emerge no contexto nacional nesse período. Há também um grupo de entrevistados(as), menos numeroso, que se inseriu no campo a partir dos anos de 1990. Contudo, é importante dizer que nenhum(a) dos(as) entrevistados(as) tem menos de 10 a 15 anos de experiência profissional.

Todos(as) têm doutorado em educação, dezesseis (16) realizados no Brasil e quatro (4) no exterior. A quase totalidade possui mestrado também na área de educação. Apenas um realizou o mestrado em filosofia, ao passo que um outro, que afirma ter feito o mestrado no exterior, não especificou a área. No que tange à formação de graduação, catorze (14) são licenciados em pedagogia, dois (2) têm dupla licenciatura - em pedagogia e em letras e em pedagogia e música - e um (1) em ciências sociais. Três (3) não mencionaram na entrevista as áreas de sua formação na graduação. Neste sentido, podemos afirmar que as trajetórias acadêmicas são consistentes e todos(as) possuem uma formação avançada na área educacional. Um número significativo dos(as) entrevistados(as) cursou a escola normal e foi professor(a) do Ensino Fundamental.

Em geral, são professores(as) com ampla experiência de ensino de graduação em disciplinas como Didática Geral, Metodologias de Ensino, Práticas de Ensino, Trabalho Docente e outras afins. Também atuam na pós-graduação, lato e stricto sensu, e estão envolvidos(as) em projetos de pesquisa e outras atividades próprias do âmbito universitário (participação em comissões, funções de coordenação em diferentes níveis, projetos de extensão etc.).

Uma característica significativa do grupo entrevistado é sua inserção em diferentes associações profissionais, sua participação em co- 
missões de órgãos federais como a CAPES e outros órgãos do MEC, o CNPq, assim como em órgãos de níveis estadual e municipal (secretarias de Educação, conselhos etc.) e organizações da sociedade civil.

Como se situam com relação ao campo da didática e à perspectiva multi/intercultural

Analisando os depoimentos, podemos constatar que o grupo entrevistado manifesta como tendência dominante uma forte identificação com o campo e sua evolução. Suas trajetórias parecem se misturar com as construções e tendências que vão marcando e/ou configurando a área de didática, principalmente a partir dos anos de 1970, quando muitos(as) deles(as) "começam" a contar suas histórias pessoais e profissionais.

\section{Sobre o campo da didática}

$\mathrm{Na}$ tentativa de melhor sistematizar as diferentes considerações feitas pelos(as) nossos(as) entrevistados(as) sobre o desenvolvimento do campo da didática, agrupamos suas reflexões em três períodos: anos de 1980, anos de 1990 e momento atual.

Assim sendo, observamos que a grande maioria deles(as) assinala a importância da década de 1980 , podendo ser esta considerada o momento de uma verdadeira "refundação" da reflexão e pesquisa da didática no país. O significado do "movimento da didática em questão" e a relevância da perspectiva crítica parecem expressar um consenso na área. Alguns(mas) entrevistados(as) apontam, também, a questão do confronto, na época, entre a pedagogia crítico-social dos conteúdos e a pedagogia libertadora como um aspecto marcante.

Os seguintes depoimentos expressam de modo significativo a postura que permeia o grupo como um todo:

O campo na década de 80 é um campo que busca muito a sua identidade. Acho que é marcado pela busca da sua identidade.

Acho que o nosso movimento da didática acompanhou esse processo [dos movimentos políticos, sociais e culturais do final da década de 1970 e início dos anos de 1980], foi sujeito e objeto. Acho que ele não foi assim um fenômeno isolado, ele veio junto do que se discutia, se misturaram um pouco 
Conversas com... sobre a didática e a perspectiva multi/intercultural

a nossa didática com a questão da CBE e depois mais tarde a ANPED e aquilo vinha num processo, assim, acho que foi um momento intelectual muito rico que a gente viveu no país com todas as suas tensões.

No campo da didática nos anos de 1980 eu tive a oportunidade de estar participando por dentro um pouco (...) num movimento muito forte, muito intenso que nós tivemos na década de 1980, sensacional, porque eu acho que a produção foi extremamente rica e nós tivemos várias elaborações e vários trabalhos que nos deram, embora tivéssemos objetivos comuns todos voltados para o desenvolvimento de uma proposta mais progressista de trabalho, essa busca de articulação de teoria e prática que era uma questão muito forte, e essa prática focalizando mesmo a prática social do sujeito Eu acho que a produção nessa época foi muito fecunda, ela se ampliou bastante, nós tivemos grupos significativos que trabalharam essas questōes.

O início da didática em questão se deu em 1982 e 1983; foram os anos da crítica da didática. Na verdade, essa análise do campo da didática começou na década de 1970, já com aquele evento que houve em Brasília (...). Assim, acho que esse movimento que começou em 1970, e depois ganhou muita força em 1980, veio culminar nisso que a gente está tendo aqui hoje (...). A primeira fase foi a da denúncia, da análise do que estava sendo o ensino da didática. A partir daí, toda a denúncia do tecnicismo. $\mathrm{Na}$ seqüência, acho que a didática passou por uma fase romântica (...), aquele sonho da transformação, a didática transformadora, que tem toda uma relação com a reorganização do país, abertura etc., e toda a movimentação social.

$\mathrm{Na}$ década de 1980, eu diria que a didática em questão, primeiro, para mim foi um marco muito grande em termos da sistematização, do processo ensino-aprendizagem, da multidimensionalidade do fenômeno educacional. Acho que isso deu uma organizada muito grande no campo. Eu acho que, para boa parte dos professores, foi um indicador forte na identidade da didática, que estava ou tecnicizada ou receituada, não sei, mais ou menos isso, ou mesmo colocada na periferia.

Oliveira, membro da mesa-redonda que no X ENDIPE, realizado no Rio de Janeiro, foi dedicada à análise dos 20 anos de produção dos ENDIPEs, na mesma perspectiva, afirma com relação à década de 1980:

Pode-se constatar, então, o fato de que, para além das diferentes posições sobre o objeto de estudo das áreas, o que existe é um grande consenso. Ele se refere à luta em defesa da legitimidade do saber didático-pedagógico, enquanto constituindo um campo de conhecimento e enquanto conteúdo do currículo da formação do educador, no contexto da luta pela especifi- 
cidade e importância do papel dos processos da educação e do ensino, no movimento de recuperação e democratização da escola pública e na transformação social. (2000, p. 164-165)

Quanto aos anos de 1990, percebemos nos depoimentos analisados uma menor convergência de idéias e, embora possamos dizer que há uma continuidade das reflexões em torno da perspectiva crítica, naquele momento, isso acontece de modo mais frágil. Sobre essa década, os(as) entrevistados(as) parecem concordar com o fato de que existe uma incorporação de novos temas, a partir de outros enfoques teórico-metodológicos, por exemplo: professor reflexivo, professor-pesquisador, identidade docente, questôes relativas ao cotidiano escolar são temas que ganham força. Poucos(as) apontam, nesse período, a permanência dos conflitos internos ao próprio campo, ao passo que outros(as) fazem referência à tensão e/ou confronto entre os campos do currículo e da didática. Para alguns(mas) entrevistados(as) começa a aparecer aqui o tema do multiculturalismo, mas ainda de modo bastante tangencial. Os depoimentos a seguir evidenciam estas posições:

Eu acho que foi uma fase de transição, no meu ponto de vista, porque, de repente, nós tivemos grandes acontecimentos que modificaram inclusive as bases referenciais e passou a se negar muitos referenciais até então constituídos para todos os trabalhos - vamos dizer assim, que era exatamente a questão do materialismo histórico-dialético, toda aquela referência mais marxista. E isso, de certa maneira, passou a ser negado, negado assim, pelo menos teve uma retração e (...) houve uma mudança nesse referencial, nesse momento. $\mathrm{O}$ que eu posso perceber é isso.

Eu acho que existe um avanço interessante na produção do conhecimento, reflexão, na busca de novos referenciais e agora nas últimas décadas, de 1990 ou da metade da década de 1990 para cá, tem todo esse movimento da reflexividade no trabalho do professor, na formação do professor.

Eu acho, assim, que dos anos de 1990 para cá, eu tenho percebido uma pulverização (num sentido positivo) de diferentes tendências. Surgiu um momento em que eu estava querendo discutir era mesmo esse objeto e tal... Eu acho que... a impressão que eu tenho é de um diálogo muito grande com diferentes perspectivas.

Acho que continua essa perspectiva de tentar discutir um objeto da didática, mas eu acho que isso perde força com o tempo e isso fica claro, apesar de ser um tema que retorna, que aparece, mas você vê ali... é tanto uma articulação com as questōes de currículo, com as questôes de formação de professores, ora isso sendo discutido dentro do GT de didática, ora 
Conversas com... sobre a didática e a perspectiva multi/intercultural

sendo discutido no GT de currículo, ora no GT de formação de professores. É uma dificuldade muito grande de limitar, de não perceber essas relaçôes, onde é que começa uma coisa e acaba a outra, principalmente nesses três campos.

E tem uma questão: acho que tem a questão toda ligada ao multiculturalismo e acho que isso aparece tanto na reflexão, nos trabalhos que a gente observa no GT, mas a gente vê as explicações, nas discussões por aí. Acho que tem toda a questão da teoria crítica que também vem via multiculturalismo, mas também tem outras aberturas que se dão, a partir daí, então, toda uma perspectiva de discutir, acho que vem muito mais pela questão do currículo, mas não deixa de estar presente na hora em que é discutida a didática, tanto que mais uma vez esses campos não estão muito limitados.

No que diz respeito ao momento atual, os depoimentos possibilitam-nos afirmar que é uma fase de muito menos confluências; alguns chegam mesmo a caracterizá-lo como um momento de "risco de dispersão": "Eu prefiro dizer, com convicção, que há um risco de dispersão. Acho que é um risco de dispersão. Acho que até o momento estamos conseguindo sustentar uma espinha dorsal do campo do didático".

Esta realidade está motivada, para alguns, por uma mudança de contexto e de referenciais teóricos:

Há uma mudança, digamos, de referencial e de contexto mesmo. Você está vivendo um novo momento agora, você já tem agora essa questão da globalização, essa questão do novo modelo, digamos, um novo momento do próprio capitalismo, com novos focos de exploração e tudo o mais, e isso muda toda uma expectativa global em termos assim "que trabalhador agora eu preciso formar? O que é importante? Qual o perfil desse trabalhador para dar conta desse momento? Etc.”. Para atender exatamente os interesses do capitalismo hoje, sempre. Então, claro que isso interfere, mas eu ainda não tive tempo para poder fazer essa elaboração, digamos.

Para outros, esse risco tem outras origens:

Mas vamos um pouquinho mais no tema do risco da dispersão. Eu tenho uma teoria pouco desenvolvida ainda que é a seguinte: no nosso país, já há uns bons anos, vem ocorrendo um processo extremamente desgastante para o campo da educação. A desqualificação econômica do magistério se projeta numa desqualificação social da profissão e acaba desqualificando o campo investigativo da área. Eu tenho essa teoria de que há algum tempo não tem dado prestígio estudar sala de aula, escola. Então, a dispersão 
temática que pode estar ocorrendo (...) se dá por razões de prestígio, na academia e tal, acabam largando a sala de aula. Porque falar didática é falar em sala de aula. E deslocam seus estudos para campos academicamente mais prestigiosos. E isso dá muito pano pra manga pra conversar (...). Quer dizer, a dispersão que está ocorrendo é menos teórica e mais social neste sentido, sociológica (...). Um outro fator desse risco de dispersão é o modismo. É evidentemente que a nossa área é uma área demasiadamente submissa aos modismos (...). Se nós formos falar de dispersão temática, nós temos que criticar o campo da educação como um todo. Então, o risco da dispersão também existe à medida que segmentos de pesquisadores entram na onda do antimarxismo. Que eu acho que é uma questão também crucial. Porque, quando colegas nossos abandonaram ou flexibilizaram a sua relação com o marxismo, claro, você perde uma referência. Podia ser marxismo, podia ser outra, se houvesse outra. No nosso caso, era o marxismo. Então, justamente por isso é que eu acho que a garantia de você segurar, vamos dizer, um núcleo duro da teoria didática está em não abandonarmos as questões epistemológicas.

Entretanto, as falas permitem-nos apontar certos elementos de continuidade, tais como: a perspectiva crítica, embora agora apareça com menos força e sob um olhar mais crítico da própria perspectiva; o cotidiano escolar; a tensão currículo-didática; e a formação de professores, com destaque para uma progressiva preocupação com as questões relativas à didática do Ensino Superior.

Por sua vez, novos elementos parecem "afetar" o campo da didática, segundo nossos(as) especialistas. São eles: a tentativa da retomada de uma visão tecnicista, em consonância com as atuais políticas de caráter neoliberal; a necessidade de busca de novos referenciais para lidar com novos contextos, novos sujeitos, novas problemáticas, como, por exemplo, a violência, os impactos provocados pelas novas tecnologias e pelos meios de comunicação de massa. Além disso, as questóes relativas ao multiculturalismo ganham maior presença, seja quando apontam o tema da diferença como uma possibilidade de enriquecimento da reflexão e ação didática, seja quando destacam suas preocupaçóes pelo deslocamento do social para o cultural.

Nos últimos anos, a partir de 1995, 1996, a gente começa a perceber novas temáticas permeando essa discussão da didática, da prática de ensino. $\mathrm{E}$ quais são esses novos requerimentos que começam a aparecer? A questão da cultura, a questão dos diferentes saberes e também a questão da violência no espaço escolar e não-escolar, enfim, então são temas que começam a aparecer 
Conversas com... sobre a didática e a perspectiva multi/intercultural

que antes a gente não via. E aí justamente toda a discussão do multiculturalismo, da questão da raça, da questão de etnia, de gênero, então começa a aparecer, ainda, eu diria, meio tangencial.

Acho que, depois de 1997, eu colocaria assim: uma visão de um sujeito histórico na área, os debates "didática e currículo", onde o conhecimento científico e as questões epistemológicas foram fundamentais para a didática incorporar um pouco mais e repensar temas ligados às questões de cultura (...). E você começa a ter uma nova agenda. Não é à toa que, se o ENDIPE de Águas de Lindóia foi a sala de aula; e se o ENDIPE de 2000 foi múltiplos olhares - então a palavra plural no multi (múltiplos olhares, múltiplos saberes, múltiplas linguagens) -, se cria um cenário favorável. E o XI ENDIPE, qual foi o tema? Igualdade e diversidade.

Quando ocorreu esse deslocamento do social para o cultural - deslocamento mesmo: do contexto para o texto, da externalidade para a internalidade, de uma visão de totalidade para uma visão de particular -, na minha maneira de ver, ocorreu um reducionismo temático, quer dizer, a questão da didática ou do currículo hoje é a cultura.

Em decorrência desses dados, cremos que podemos afirmar que, em geral, nossos(as) entrevistados(as) não parecem situar-se numa relação de ruptura da perspectiva crítica, embora a adesão a ela seja menos enfática. Em contrapartida, um número significativo parece apontar para a necessidade de repensá-la e/ou ressignificá-la, em conseqüência dos novos desafios postos pela contemporaneidade.

Diante dessas nossas observações e/ou análises, somos provocadas a levantar algumas novas questôes: Estaríamos vivendo um momento de crise paradigmática e/ou de desestabilização do campo? Trata-se de identificar germens da emergência de um novo paradigma ${ }^{1}$ ou de caminhar no sentido da ressignificação da perspectiva crítica?

No âmbito deste trabalho, acreditamos que é suficiente ou apenas possível fazer estas perguntas. Suas respostas, certamente, exigirão novas pesquisas e reflexões. Nossa intenção, neste caso, é apenas abrir mais uma porta para o debate.

\section{Sobre as relações entre didática e multi/interculturalismo}

Para alguns(mas) de nossos(as) entrevistados(as), apesar de o tema do multiculturalismo ter aparecido no campo da didática na segunda metade da década de 1990, ainda é hoje objeto de preocupação de poucos grupos e sua presença pode ser caracterizada como uma 
temática que se situa à margem, embora num movimento de afirmação. O depoimento a seguir ilustra estas considerações. "Em geral eu acho que sim... Na didática é que está muito amarrado ainda. Eu acho que é um grupo muito pequeno ainda que está tentando... com sensibilidade para essa questão".

Alguns(mas) entrevistados(as) observam também que o multiculturalismo afeta mais o plano teórico do que a prática educativa. E, neste sentido, estes outros relatos são bem expressivos.

Eu diria que sim, está presente no discurso profissional dos formadores e das instituições. Quando você tem o relato de como as disciplinas estão sendo desenvolvidas e de como os cursos estão sendo avaliados, eu não percebo isso (...). Em termos institucionais, no discurso está muito presente. Agora, as práticas continuam as mesmas.

(...) quando você fala de multiculturalismo e didática, o fato de ainda estarmos nesse ponto que nós estamos [ela/ele está se referindo ao fato de o multiculturalismo ainda estar na academia e sob o domínio de poucos grupos], isso incomoda. Porque a didática exige uma ação prática. Só o discurso sobre o multiculturalismo não é suficiente para dizer a didática está assim... está assim...

Os(as) especialistas dizem também que o multiculturalismo está mais na academia que nas escolas. E, especificamente, mais na pesquisa que no ensino. Na escola ou no ensino sua presença é caracterizada como pontual.

Aprofundando essa relação entre didática e multiculturalismo, os(as) professores(as) e pesquisadores(as) entrevistados(as) ressaltam outros aspectos que cremos poderem ser assim explicitados: o multiculturalismo lida com um referencial teórico complexo e mais vinculado ao discurso da desconstrução. Além disso, seria necessário enfrentar a tensão entre Teoria Crítica, Multiculturalismo e Estudos Culturais. Para alguns(mas), o conhecimento organizado sobre multiculturalismo é algo recente, no entanto as discussões entre educação, escola, sociedade e diferentes grupos socioculturais já estariam postas pela teoria crítica.

Todavia, os(as) entrevistados(as) apontam, embora de modo bastante disperso, possíveis contribuiçôes da perspectiva multi/intercultural, como, por exemplo: mesmo considerando que há diferentes visões sobre a diferença, ela está presente no cotidiano escolar e é preciso trabalhá-la. A perspectiva multicultural pode ajudar nesse enfrentamen- 
Conversas com... sobre a didática e a perspectiva multi/intercultural

to, assim como pode auxiliar a compreender melhor como se dá o fracasso escolar.

Além disso, tal perspectiva favoreceria a retomada da discussão sobre os conteúdos escolares, ofereceria elementos para se trabalhar questões como violência e disciplina, preconceito e discriminação, bem como poderia desvelar questóes étnicas e de gênero presentes na escola, ajudando a "ver" e "lidar" com as diversidades presentes na sala de aula e, neste sentido, ajudaria a romper com o que Cortesão e Stoer (1999, p. 56) chamam de "daltonismo cultural".

E mais, estimula a ruptura com a homogeneização - lógica que configura de modo bastante cristalizado a cultura escolar e que, talvez, seja difícil de romper, já que a busca pela homogeneização das turmas, sabemos, é cultural e secular.

Outras contribuiçôes estão associadas à possibilidade que essa perspectiva tem de despertar para as questôes relativas às diferentes linguagens presentes no cotidiano escolar, bem como de articular o social e o cultural. Alguns depoimentos, em particular, parecem expressar o "tom" dessas contribuiçóes: "O multiculturalismo é uma atitude, um modo de ver a realidade e a sociedade e, portanto, um olhar que impregna toda a prática pedagógica"; "Ele ajuda a ressignificar a prática didática".

Em contrapartida, podemos ainda ressaltar que nossos(as) entrevistados(as) apontam alguns riscos no que tange à adoção de uma perspectiva multi/intercultural. Assim alguns(mas) deles(as) falam sobre o perigo de: ser um modismo, situar-se em uma lógica de importação, sem dialogar de modo mais profundo com as diferentes configuraçōes do multiculturalismo na nossa sociedade; ser disciplinarizado e reduzido a um conhecimento específico; exacerbar a diferença, provocando certos antagonismos ou ficar somente no respeito à diferença, sem com ela dialogar; ficar no plano conceitual e esquecer de que a diferença é inerente à dinâmica concreta das nossas escolas e salas de aula; desvincular a dimensão cultural da questão social/de classe e, assim, absolutizar a questão multicultural.

Ao lado desses riscos, quando o tema é a relação entre didática e multiculturalismo, assinalam que alguns desafios podem também ser constatados. Quando, por exemplo, registramos depoimentos que apontam a necessidade de romper com a idéia de que a diferença é um problema, ou seja, uma dificuldade, uma vez que, no imaginário presente 
na cultura docente, a homogeneização seria um fator de facilitação do trabalho pedagógico. Outro desafio está associado à necessidade de buscar trabalhar de modo mais efetivo a articulação entre multiculturalismo e os chamados temas próprios da didática - planejamento, seleção de conteúdos, técnicas de ensino, avaliação etc. O que significa dizer que os estudos e as pesquisas sobre o multiculturalismo ainda não teriam afetado o núcleo central da didática e da prática pedagógica. Também se configuram como questôes desafiadoras a concepção e a produção de materiais didáticos mais adequados.

Gostaríamos ainda de assinalar uma preocupação explicitada com maior veemência por um(a) de nossos(as) entrevistados(as). Trata-se da necessidade de enfrentar a discussão entre a função social da escola e o multiculturalismo, principalmente no que se refere à apropriação de conhecimentos.

(...) ainda não desmontei isso da minha cabeça... A melhor maneira das escolas ajudarem a democracia, dar instrumentos de luta para os pobres... A melhor coisa que a escola pode fazer é produzir alunos que tenham uma sólida formação científica, cultural e competências, capacidade de pensar, para poder se integrar ao mercado de trabalho, para poder participar politicamente e culturalmente da sociedade... Tudo aquilo que desfaz, tudo aquilo que não leva a isto, tudo aquilo que compromete isso... Tudo que é contra isso é excludente... Você pensa que são formas includentes, mas acabam sendo, novamente, políticas compensatórias.

$\mathrm{E}$, mais especificamente, de enfrentar a tensão entre universalismo e relativismo cultural: "O relativismo cultural e ético é uma bomba na educação e na escola, e esse relativismo está penetrando na cabeça do professor... É uma bomba na sua cabeça...”.

Para concluir esta etapa de análise do material das entrevistas, cremos que ainda vale sublinhar uma outra tensão que nos parece também objeto das preocupaçóes dos(as) especialistas. Ao mesmo tempo em que reconhecem a importância da dimensão cultural, estão sempre se referindo às desigualdades sociais, de classe, de oportunidades sociais e educacionais e de sua relação com o contexto de pobreza estrutural da sociedade brasileira. Parece-nos que o confronto social versus cultural está na base desses comentários, ora percebido como uma questão: "Será que no Brasil temos de falar de multiculturalismo ou de desigualdade social?", ora como um desafio, já que tal perspectiva pode provocar-nos no sentido de 
Conversas com... sobre a didática e a perspectiva multi/intercultural

mobilizar processos de articulação entre igualdade e diferença e não de considerá-los pólos contrapostos.

\section{Considerações finais}

Por intermédio da análise dos depoimentos dos protagonistas do campo da didática, é possível afirmar que o impacto da perspectiva multi/ intercultural é reconhecido por estes atores, apesar do seu aspecto ainda frágil e embrionário. Várias contribuições são identificadas no sentido de problematizar a cultura escolar dominante nas nossas escolas, de caráter homogeneizador e monocultural, e de enfrentar a questão da relação entre diferença e ação educativa. Afinal, como afirma um(a) dos(as) entrevistados(as): "A diferença está no chão da escola". Esta expressão condensa de modo particularmente rico uma afirmação básica para a construção de uma didática na perspectiva multi/intercultural: a questão da diferença não é um componente externo, recentemente incorporado à reflexão pedagógica, mas um componente configurador de sua própria realidade. Negada, naturalizada ou reduzida a uma dimensão psicológica ou social, a diferença é constitutiva da prática pedagógica. De fato, a questão da diferença na educação não é um problema inédito, tampouco se pretende ignorar as importantes teorizações já construídas a esse respeito. Como afirma Gimeno Sacristán, referindo-se a essa mesma discussão: "Não convém anunciar esses problemas como sendo novos, nem lançá-los como moda, perdendo a memória e provocando descontinuidades nas lutas para mudar as escolas" (2002, p. 15). No entanto, a reflexão atual enfatiza o caráter histórico e sociocultural da construção das diferenças. Elas se constituem no âmago das relaçôes sociais, nas lutas por reconhecimento dos diferentes grupos sociais e étnicos. Neste sentido, a dimensão cultural adquire especial relevância.

Junto de uma posição de valorização das contribuições da perspectiva multi/intercultural, também são colocadas pelos(as) entrevistados(as) questôes de fundo de particular importância. Queremos assinalar principalmente três: a articulação entre igualdade e diferença, a tensão entre o social e o cultural, assim como a problemática do universalismo versus relativismo cultural em suas relações com a escolarização.

Estes são aspectos que consideramos fundamentais e que vimos trabalhando em nossa linha de pesquisa na perspectiva da superação de uma visão dicotômica e da afirmação da necessidade de trabalhar estas ten- 
sões e a articulação entre esses diferentes pólos. Isso supõe um processo de desconstrução da visão dominante na cultura escolar, em que os chamados valores e conhecimentos considerados universais não são problematizados: muitas vezes são vistos numa abordagem a-histórica e consensual, a afirmação das variáveis de caráter social não é articulada com questôes de etnia, gênero, grupo sociocultural de referência e orientação sexual, e a defesa da igualdade silencia e nega as diferenças. Discutir esses temas, ser consciente de que a escola realiza uma seleção cultural que não é neutra, é uma tarefa urgente.

Neste horizonte de preocupações, afirmamos a necessidade de ressignificar a perspectiva crítica no âmbito da educação e da didática. Não se trata de negá-la - nossos entrevistados e nós mesmas estamos arraigados nesta tradição -, mas sim de favorecer um processo de reconfiguração em que propomos que a perspectiva multi/intercultural constitua o eixo central desse processo. Para tal, tendo presente os depoimentos analisados, reafirmamo-nos em alguns componentes que consideramos fundamentais na construção de uma educação e de uma didática na perspectiva multi/intercultural (Candau, 2005, p. 33-35):

Em recente trabalho, apresentado no II Seminário Internacional sobre Educação Intercultural, Gênero e Movimentos Sociais, promovido pela Universidade Federal de Santa Catarina, realizado em Florianópolis, de 8 a 11 de abril de 2003, enumeramos alguns dos desafios que temos de enfrentar se quisermos promover uma educação intercultural na perspectiva crítica e emancipatória, que têm emergido das pesquisas e dos trabalhos que vimos realizando. Foram agrupados em torno de determinadas açôes que consideramos fundamentais: desconstruir, articular, resgatar e promover. São eles:

DesConstruir

- Penetrar no universo de preconceitos e discriminaçóes presentes na sociedade brasileira. Essa realidade se apresenta entre nós com um caráter difuso, fluído, muitas vezes sutil, e está presente em todas as relaçōes sociais. A "naturalização" é um componente que a faz em grande parte invisível e especialmente complexa. Para a promoção de uma educação intercultural é necessário reconhecer o caráter desigual, discriminador e racista da nossa sociedade, da educação e de cada um(a) de nós. Desenvolver estratégias nessa perspectiva é fundamental.

- Questionar o caráter monocultural e o etnocentrismo que, explícita ou implicitamente, estão presentes na escola e nas políticas educativas, e 
Conversas com... sobre a didática e a perspectiva multi/intercultural

impregnam os currículos escolares. Perguntarmo-nos pelos critérios utilizados para selecionar e justificar os conteúdos escolares.

ARTICULAR

- Articular igualdade e diferença: é importante articular no nível das políticas educativas, assim como das práticas pedagógicas, o reconhecimento e a valorização da diversidade cultural, com as questóes relativas à igualdade e ao direito à educação, como direito de todos(as).

RESGATAR

- Resgatar os processos de construção das nossas identidades culturais, tanto no nível pessoal como no coletivo. As histórias de vida e da construção de diferentes comunidades socioculturais são elementos fundamentais nessa perspectiva. Especial atenção deve ser dada aos aspectos relativos à hibridização cultural e à constituição de novas identidades culturais. É importante que se opere com um conceito dinâmico e histórico de cultura, capaz de integrar as raízes históricas e as novas configuraçôes, evitando-se uma visão das culturas como universos fechados e em busca do "puro", do "autêntico" e do "genuíno", como uma essência preestabelecida e um dado que não está em contínuo movimento.

PROMOVER

- Promover experiências de interação sistemática com os "outros": para sermos capazes de relativizar nossa própria maneira de situarmo-nos diante do mundo e atribuir-lhe sentido, é necessário que experimentemos uma intensa interação com diferentes modos de viver e expressar-se. Não se trata de momentos pontuais, mas da capacidade de desenvolver projetos que suponham uma dinâmica sistemática de diálogo e construção conjunta entre diferentes pessoas e/ou grupos de diversas procedências sociais, étnicas, religiosas, culturais etc. Exige romper toda tendência à guetificação, presente também nas instituições educativas, e supõe um grande desafio para a educação.

- Reconstruir a dinâmica educacional: a educação intercultural não pode ser reduzida a algumas situações e/ou atividades realizadas em momentos específicos, nem focalizar sua atenção exclusivamente em determinados grupos sociais. Trata-se de um enfoque global, que deve afetar todos os atores e a todas as dimensóes do processo educativo, assim como os diferentes âmbitos em que ele se desenvolve. No que diz respeito à escola, afeta a seleção curricular, a organização escolar, as linguagens, as práticas didáticas, as atividades extraclasse, o papel do professor, a relação com a comunidade etc.

- Favorecer processos de "empoderamento", principalmente orientados aos atores sociais que historicamente tiveram menos poder na sociedade, ou seja, menores possibilidades de influir nas decisões e nos processos 
coletivos. O "empoderamento" começa por liberar a possibilidade, o poder, a potência que cada pessoa tem, para que ela possa ser sujeito de sua vida e ator social. O "empoderamento" tem também uma dimensão coletiva, trabalha com grupos sociais minoritários, discriminados, marginalizados etc., favorecendo sua organização e participação ativa na sociedade civil.

Recebido em abril de 2006 e aprovado em maio de 2006.

Nota

1. Entendemos paradigma, na perspectiva de Kuhn (1962), como "toda constelação de crenças, valores, técnicas etc. partilhadas pelos membros de uma comunidade determinada (...). Um paradigma é aquilo que os membros de uma comunidade científica partilham $\mathrm{e}$, inversamente, uma comunidade científica consiste em homens que partilham um paradigma" (p. 218-219).

Referências bibliográficas

ABDALLAH-PRETCEILLE, M. La educación intercultural. Barcelona: Idea Books, 2001.

BANKS, J.A. An introduction to multicultural education. Boston: Ally \& Bacon, 1999.

BARTOLOMÉ PINA, M. Diagnóstico a la escuela multicultural. Barcelona: CEDECS, 1997.

CANDAU, V.M. A didática hoje: uma agenda de trabalho. In: CANDAU, V.M. et al. Didática, currículo e saberes escolares. Rio de Janeiro: DP\&A, 2000 .

CANDAU, V.M. (Org.). Sociedade, educação e cultura(s): questões e propostas. Rio de Janeiro: Vozes, 2002.

CANDAU, V.M. Relatório da Pesquisa Universidade, Diversidade Cultural e Formação de Professores. Rio de Janeiro: Departamento de Educação da PUC-RIO, 2003.

CANDAU, V.M. Sociedade multicultural e educação: tensões e desafios. In: Candau, V.M. (Org.). Cultura(s) e educação: entre o crítico e o pós-crítico. Rio de Janeiro: DP\&A, 2005. 
Conversas com... sobre a didática e a perspectiva multi/intercultural

CANDAU, V.M. (Org.). Cultura(s) e educação: entre o crítico e o póscrítico. Rio de Janeiro: DP\&A, 2005.

CANCLINI, G.N. Consumidores e cidadãos: conflitos multiculturais da globalização. Rio de Janeiro: UfRJ, 1995.

CANCLINI, G.N. Culturas híbridas. São Paulo: edusp, 1997.

CANCLINI, G.N. La globalización imaginada. Buenos Aires: Paidós, 1999.

CORTESÃO, L.; STOER, S. "Levantando a pedra": da pedagogia inter/ multicultural às políticas educacionais numa época de transnacionalização. Porto: Afrontamento, 1999.

FORQUIN, J. Escola e cultura: as bases sociais e epistemológicas do conhecimento escolar. Porto Alegre: Artes Médicas, 1993.

FORQUIN, J. O currículo entre o relativismo e o universalismo. Educação \& Sociedade, Campinas, v. 21, n. 73, p. 79-83, dez. 2000.

GARCIA CANCLINI, N. Los estúdios culturales de los 80 a los 90: perspectivas antropológicas y sociológicas en América Latina. Punto de Vista, n. 90, set. 1991.

GIMENO SACRISTÁN, J. A construção do discurso sobre a diversidade e suas práticas. In: Alcudia, R. et al. Atenção à diversidade. Porto Alegre: ARTMED, 2002.

HALL, S. A identidade cultural na pós-modernidade. Rio de Janeiro: DP\&A, 1997a.

HALL, S. A centralidade da cultura: notas sobre a revolução do nosso tempo. Educação \& Realidade, Porto Alegre, v. 22, n. 2, p. 15-46, jul./dez. $1997 b$.

JORDAN, J.A. Propuesta de educación intercultural para profesores. Barcelona: CEAC, 1996.

KUHN, T. A estrutura das revoluções científicas. São Paulo: Perspectiva, 1962.

McLAREN, P. Multiculturalismo crítico. São Paulo: Cortez, 1997. 
McLAREN, P. Multiculturalismo revolucionário: pedagogia do dissenso para o novo milênio. Porto Alegre: Artes Médicas, 2000.

OLIVEIRA, M.R.N.S. 20 anos de ENDIPE. In: CANDAU, V.M. et al. Didática, currículo e saberes escolares. Rio de Janeiro: DP\&A, 2000.

SANTOS, B.S. Uma concepção multicultural dos direitos humanos. Lua Nova - Revista de cultura e política, São Paulo, n. 30, p. 105-124, 1997.

SANTOS, B.S. (Org.). Reconhecer para libertar: os caminhos do cosmopolitismo multicultural. Rio de Janeiro: Civilização Brasileira, 2003. 